\title{
Temporary Classroom After the Earthquake in Lombok
}

\author{
Inggit Musdinar S.S.Y.M \\ Dept. of Architecture \\ Universitas Budi Luhur \\ Jakarta, Indonesia \\ inggit.musdinar@budiluhur.ac.id
}

\begin{abstract}
The earthquake that happened in Lombok Island on July 29, 2018, caused damage to buildings and stopped the educational activities. Badan Nasional Penanggulangan Bencana (BNPB) announced that there were 606 school buildings damaged by the Lombok earthquake, with a total of 3,051 classrooms damaged. Steps taken by the government so that educational activities can take place, which is also a trauma therapy tools for students is to establish a Temporary Classroom. This study uses simulative methods and experimental methods, in which the relationship between variables is known by conducting simulations in the Temporary Classroom using SAP 2000 software and Truss D\&E software. The simulation results will be determined as a guideline in the construction of the Temporary Classroom held in Lombok. While the experimental method is applied by constructing a Temporary Class building model with a scale of 1: 1 in one of the affected schools. The objectives of this research achievement are in the form of; i) identification and collection of data in the form of literature studies related to the selection of lightweight and easy structural materials, ii) identification and collection of earthquake affected school locations, iii) observing study cases in the form of photographs and working drawings, iv) simulations using the aid of devices SAP 2000 and Truss D\&E software, $v$ ) data analysis and processing of results from software simulations, vi) formulation of results to be used as a guide in building Provisional Classes. The results of this study were to obtain guidelines for the implementation of Temporary Classes with structural planning which began using the Truss Quick Series software and SAP 2000 software. In addition, the results were expected to contribute to scientific writing relating to Temporary Buildings in earthquake prone areas.
\end{abstract}

Keywords: earthquake, temporary buiding, lightweight structure

\section{INTRODUCTION}

A magnitude 6.4 earthquake struck Lombok (West Nusa Tenggara) and Bali. Reporting from the BBC, as of 31 July 2018, the number of victims evacuated at the shelter reached more than 5,000 people in Lombok. This earthquake also resulted in 436 people died, more than 1,393 people were injured, 22,000 houses were damaged, and 8 points of the village were destroyed, including: Calabai, Karombi, West Kadindi, Nangamiro, East Kadindi, Tambora, Pekat, and Sorinomo.

Indonesia is a country consisting of a group of islands separated by shallow seas and earthquakes are a common disaster in countries whose territories are islands. The earthquake in Lombok affected all physical buildings, both residential, public facilities and infrastructure. And evacuation measures are carried out by accommodating refugees in temporary buildings, until the permanent buildings have been rebuilt.

Since the earthquake and aftershocks were hit, the people of Lombok have not been able to move normally in a short time, considering that physical development takes time. In addition to post-disaster trauma recovery, refugees also need health facilities. And no less important is educational facilities. Because refugees also consist of school-age children.

Therefore the government through the Ministry of Education and Culture provides temporary educational facilities. The criteria for building temporary educational facilities include: the construction process does not take long, uses a lightweight structure, and can function optimally as a class. And the embodiment of what has been determined then it takes a simulation to test technically, so that even though the building is temporary, it remains safe when functioning.

\section{TEMPORARY CLASSROOM}

Since the earthquake and aftershocks were hit, the people of Lombok have not been able to move normally in a short time, considering that physical development takes time. In addition to post-disaster trauma recovery, refugees also need health facilities.

And the no less important is educational facilities. Because refugees also consist of school-age children. Temporary classrooms are classrooms that are only used temporarily as post-earthquake education facilities. Temporary classroom expected to be a therapy for schoolage children who are victims of the disaster [1]. 
building system that is established. Light structures are also grouped according to the type of material, where this type of material will affect the stretch to be achieved and the building's façade [4]. Law Number 28 of 2002 in article 7 (seven) paragraph 5 (five), namely:

Semi-permanent buildings are buildings that are used for functions that are determined by semi-permanent construction or which can be upgraded to permanent.

Emergency buildings are buildings whose functions are only used temporarily, with impermanent construction or not long-lived buildings, for example, keet directors and temporary shelter kiosks.

Regional Governments can designate a location as a disaster area and set a prohibition to build at a certain time limit or unlimited with consideration of safety and security in the public interest or establish specific requirements for development procedures if the area has been deemed not dangerous.

Buildings damaged by disaster are permitted to carry out emergency repairs or erect temporary buildings for emergency needs within a certain time limit, and the Regional Government may free up and / or ease the licensing provisions but with due regard to security, safety and human health.

The Regional Government's policy together with the community is obliged to arrange the buildings mentioned above in order to guarantee the security, safety, and convenience, as well as the harmony and harmony of the building with the architecture and the environment around it.

According to what is stated in the aforementioned Law, the Regional Government takes the quick step of establishing a temporary classroom to maintain the continuity of learning activities. This temporary classroom building also embodies disaster response actions and helps the continuation of the process of educational activities in the affected area of Lombok [2].

\section{Temporary Building Structure}

Temporary classrooms as discussed earlier, are temporary. Its function is to facilitate activities during the construction process of permanent classrooms.

Consideration of the selection of appropriate material will certainly greatly affect the level of ease and time-efficient processing. From the material that has been determined, one by one the material has been determined, both in terms of advantages and disadvantages of the material that has been determined. Because when the material is mixed into a system, of course it must be responsible for its safety. In addition, spatial requirements which include: lighting and manners must still be met, to ensure that educational activities can continue well even in temporary containers [3].

\section{Basic Reqiurement of Temporary Classroom in Lombok}

\section{a. Light Structure}

Light structure can be understood that the structure does not cause a significant burden on the

\section{b. Classroom Requirement} building planning and design, in addition to the function of the building as a container for an activity. And the comfort of this space can be achieved if it is met the criteria for space requirements, namely: lighting, air conditioning, and noise level control.

Otherwise in the planned temporary classroom building is an educational facility, lighting, lighting, and noise control are absolutely taken into consideration. This is closely related to the success of the temporary building as an educational facility.

Lighting requirements are lighting requirements that must be provided in buildings through natural lighting and / or artificial lighting, including emergency lighting. For an educational facility the lighting requirements must meet the standard requirements for reading and writing. This can be realized through the size of openings that distribute sunlight into the room.

Air conditioning requirements are efforts to achieve comfort in the air conditions in the room. Even though the classroom building is only temporary, nonetheless the mandatory requirements must still be sought for the implementation of the building's functions.

Next is the noise control requirements which include: comfort level of vibration and noise. The intended comfort requirements are determined by a condition that does not cause the user and the function of the building to be disturbed by vibrations or noise arising from both inside the building and its environment.

Researchers use existing data in the field to evaluate the Provisional Classroom whether it is sufficient in terms of security of lightweight structures and time-efficient in the process. Based on the results of the analysis of this study, it is expected that in the future it can be used as a reference in the construction of other temporary buildings.

\section{RESEARCH METHOD}

The research method used for this research is a quantitative method through simulative and also experimental methods, where temporary classroom buildings are evaluated using the Truss Quick Series software and SAP 2000 , then the simulation results are compiled into a framework that contains structural calculations and drawings details are used as technical guidelines for the construction of temporary classrooms. In this case the meantime classroom building is a temporary classroom building located in an earthquake-affected area on Lombok.

a) Quantitative Methods

To carry out quantitative methods, researchers use the following steps:
Convenience is an indicator of the success of 
adjusted to the height of the building without the need to cut so that it is more effective and efficient.

Deficiency :

The wall of this GRC board is thin ie only has a thickness of $10 \mathrm{~mm}$

\section{b. Roof Material}

The choice of roof cover type is closely related

b) Experimental Method by making a 1: 1 scale Mock-Up Building in Lombok using guidelines from the simulation software output used.

\section{Simulation Object}

In this study, the simulation object is in the form of temporary classrooms in which earthquake affected areas in Lombok are built in large quantities in a short period of time. Temporary classrooms are set up in sizes $7 \mathrm{~m} \mathrm{X} 9 \mathrm{~m}$ using lightweight steel main frame, sheathing or wall materials using GRC boards and roof coverings with Spandek in the shape of a gable roof[5].

\section{RESULTS AND DISCUSSION}

This writing is intended to evaluate and provide suggestions in the form of guidelines for the construction of Temporary Classroom buildings, which use lightweight structures and the process does not require a long time.

\section{Temporary Classroom Material}

Material used for buildings in areas affected by earthquakes as classrooms, even if they are temporary buildings, refers to lightweight structure materials. Then it can be observed in the following data that the ingredients are applied there[6].

a. Wall Material

\section{GRC Board}

GRC Board (Glass-fiber Reinforced Cement Board or fiber glass cement board) is a new innovation fiber-glass cement board. GRC boards are designed with a high level of density and strength. GRC boards are recommended for interior and exterior applications and wet areas such as ceilings on ( kitchen, terrace, bathroom), partitions, etc.

Material physical data:

Standard thickness: $4 \mathrm{~mm}$.

Standard dimensions: 600x1200mm and 1220x2440mm.

Standard thickness: 5 (fiberlux), 6.8 and $10 \mathrm{~mm}$.

Standard dimensions: 1220x2440mm.

\section{Advantages :}

The advantages of GRC board walls are that they are easy to work on, easy to cut and install. This wall does not need to be plastered or curled, paint finishing process can be continued after installation, the module size can be to the achievement of comfort requirements as a Temporary Classroom. However, those who meet the lightweight structure requirements are the following roof materials:

Spandek

Material physical data

\begin{tabular}{|c|c|}
\hline Basic materials & High - Tensile Steel \\
\hline Melting voltage & $550 \mathrm{MPa}\left(\mathrm{N} / \mathrm{mm}^{2}\right)$ \\
\hline Protected Layer & $\begin{array}{c}\text { Zinc-Aluminum } \\
\text { Prepainted Zinc-Aluminum } 150 \mathrm{gr} / \mathrm{m}^{2}\end{array}$ \\
\hline Thickness Standard & $\begin{array}{l}0,40 \mathrm{~mm} \text { BMT atau } 0,45 \mathrm{~mm} \text { TCT } \\
0,45 \mathrm{~mm} \text { BMT atau } 0,50 \mathrm{~mm} \text { TCT } \\
0,50 \mathrm{~mm} \text { BMT atau } 0,55 \mathrm{~mm} \text { TCT }\end{array}$ \\
\hline Wave Height & $40 \mathrm{~mm}$ \\
\hline Effective Width & $660 \mathrm{~mm}$ \\
\hline Material Standart & SNI 4096-200 \\
\hline
\end{tabular}

Advantages:

The first advantage of a spandek roof is that it is easy to install. It doesn't take long to cover the entire top of the house with an uncomplicated frame structure. instead of using tile or other types of roofing because spandek roofs can reduce the risk of collapse of the roof.

The average thickness of a spandek roof is around $0.3 \mathrm{~mm}$ to $0.5 \mathrm{~mm}$. indeed classified quite thin, but that does not mean this roof is easily destroyed. Spandek roof has anticracking and anti-cracking properties due to the basic ingredients.

Deficiency: roof of the spandek can cause noise that reduces comfort in the classroom. Besides thin, light weight is also a factor that causes the spandek roof has a much higher noise level than any other type of roof.

The room temperature below is quite high in hot weather. Zinc and aluminum metals are indeed materials that have good heat conductor properties. This will cause heat in the room under spandek tile. High spacing and coated aluminum foil on the underside of the tile can help reduce high temperatures.

c. Main Structure Material

Light steel

Mild steel is one of the world construction materials, which is often referred to as a substitute for wood material which is now increasingly difficult to obtain both in terms of availability and price.
This thin roof is not a good silencer. If heavy rain hits the 
Mild steel has several types of profiles. One of the mild steel profiles is channel $\mathrm{C}$. Canal $\mathrm{C}$ has a profile such as the letter $\mathrm{C}$ and its size is distinguished according to the size of its thickness. Measuring the thickness of the mild steel $\mathrm{C}$ channel shape are generally $0.60 \mathrm{~mm}, 0.75$ $\mathrm{mm}$ and $1 \mathrm{~mm}$. Different thickness sizes are used for different things. For example, the form of mild steel canal $\mathrm{C}$ size $0.75 \mathrm{~mm}$. In general, channel $\mathrm{C}$ with a size of 0.75 $\mathrm{mm}$ is used for making horses on the roof with a light load. For example, only metal tile, asbestos, spandek and other lightweight roofs. Anal C $75 \times 0.75$ can also be used to double ceiling and column buildings and partition walls and windows.

Application of mild steel as a column in the classroom by combining $2 \mathrm{C}$ channels into one (box) as the main carrying capacity of emergency buildings.

For C 75 canals with a thickness of $1 \mathrm{~mm}$ it is generally used as a truss for heavy roof coverings, such as ceramic roof tiles, concrete roof tiles, earth roof tiles and other tiles weighing over $59 \mathrm{~kg}$ wet.

Advantages:

Light steel is easy to work on, suitable for Emergency Classroom buildings with a span of $7 \mathrm{~m}$. Affordable prices and many availability and easy to obtain.

Deficiency:

Mild steel has less aesthetic value and is not easy to do finishing.

\section{Temporary Classroom in Lombok}

Of the material applied to temporary classrooms in Lombok. The following is figure 1 (one) temporary class module which is the object of simulation. Temporary classrooms use the shape of the gable and the size of the room (7 X 9) $\mathrm{m} 2$.

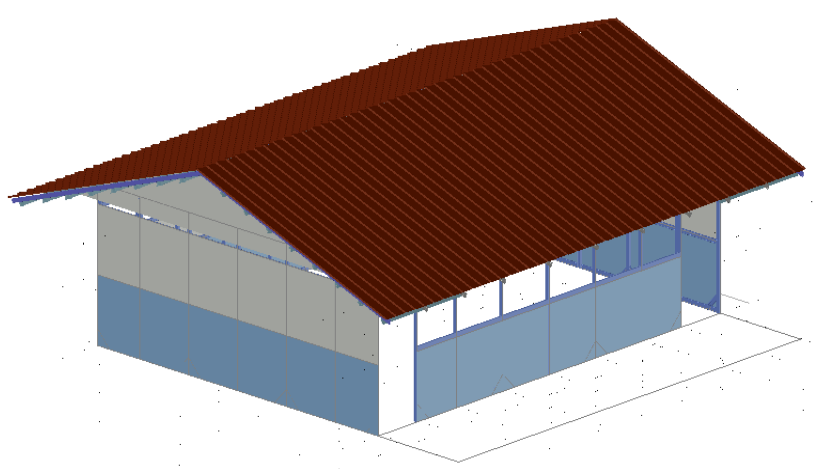

Figure 1. Temporary Classroom Perspectives

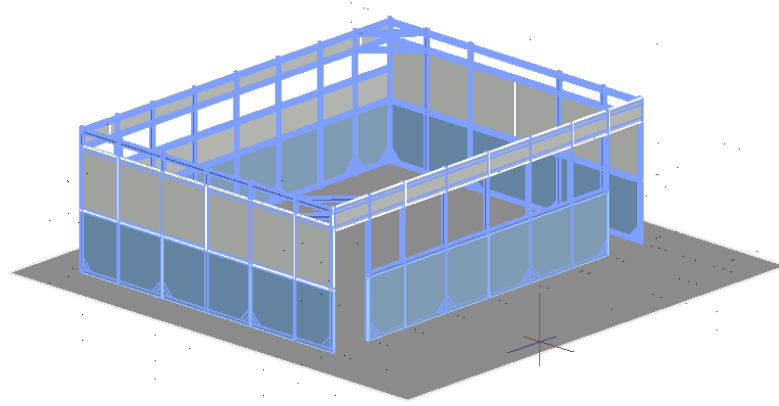

Figure 2. Temporary Classroom Column Module

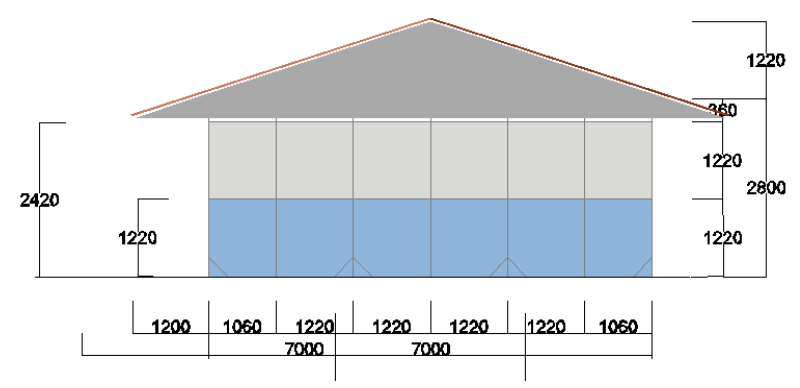

Figure 3. Side View of Temporary Classrooms

This Temporary Classroom is also equipped with openings, so that on the two sides of the wall there are parts which are not all covered. Openings can be in the form of windows and vents.

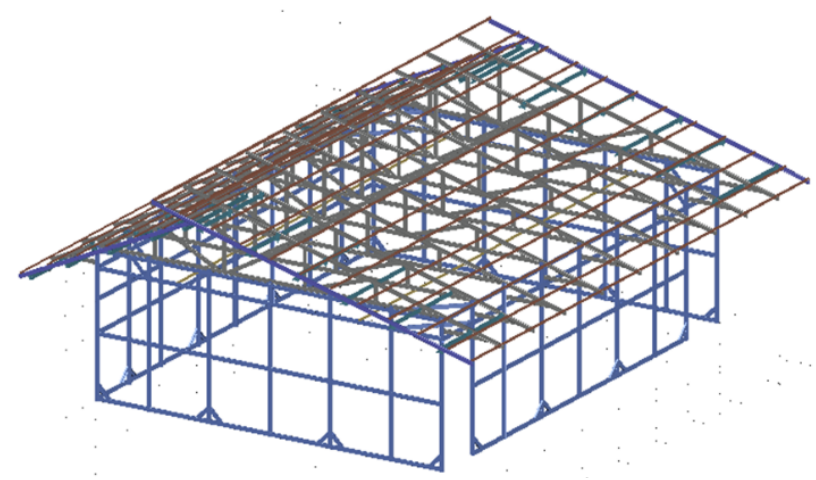

Figure 4. Temporary Classroom Frame System

\section{Simulation using software}

Guided by the initial criteria that temporary classrooms must be easy in the process of work, then the proposed emergency classroom design with the shape of a gable roof. Furthermore, the simulation will be carried out using the Truss D\&E and SAP 2000 devices.

D\&E Truss Software is software that can be used to simulate web design on roof truss systems that use lightweight steel material. Whereas SAP 2000 is software that can be used to carry out simulations on a frame system that is applied to Temporary Classroom buildings.

\section{Simulation Results with D\&E Truss Software}

This D\&E Truss software helps analysis on roof structures with mild steel material. The following are the results of the analysis: 


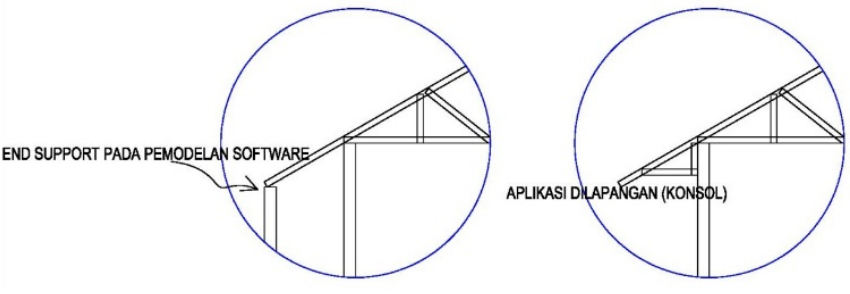

Figure 7. Adaptation of consuls from the simulation results to the field application.

\section{Simulation Results with SAP 2000 Software}

In addition to using Truss D\&E software, simulations on the design of temporary classrooms are also carried out using SAP 2000 tools. The results of the analysis using SAP 2000 software are as follows:

\section{Section $3 \mathrm{D}$}

The analysis is done by including the design of the wall frame and roof frame design in 3D in SAP 2000 software.

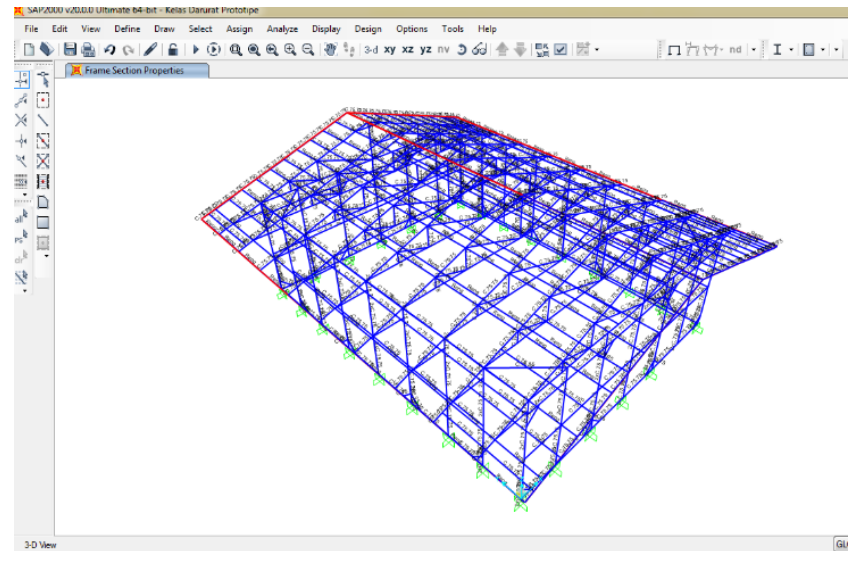

Figure 8. Output of SAP 2000 System Frame Simulation.

2. Section $2 \mathrm{D}$

Analysis can also be seen per module easel in 2D form. In the Provisional Classroom there is only 1 type of easel because it uses the shape of a gable.

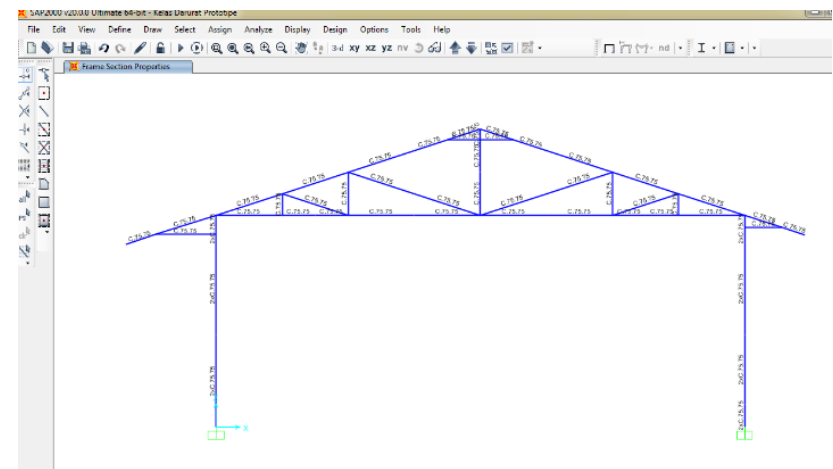

Figure 9. 2D Output Section Simulation of SAP 2000.

3. Translation of the results of the analysis with the implementation in the field

In the picture in the Truss D\&E software there is support at the overstek end, even though the implementation process requires that there are no columns at the overstek end. Then the solution is to use a console.

Figure 6. Output of the simulation Truss D\&E calculation based on specifications. 
3. Light steel material input specifications

Next is filling the material specifications used, namely mild steel with a thickness of $1 \mathrm{~mm}$.

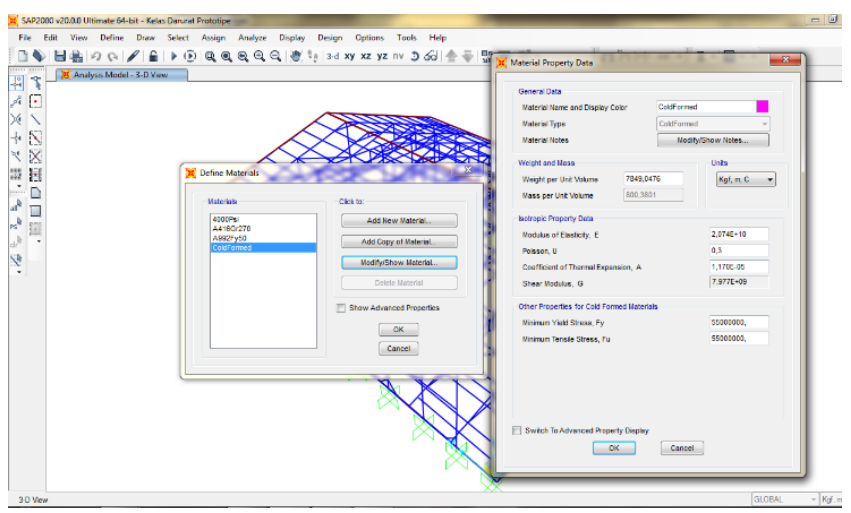

Figure 10. Input material specification data.

4. Enter the profile of the mild steel material used which is C 0.75 .

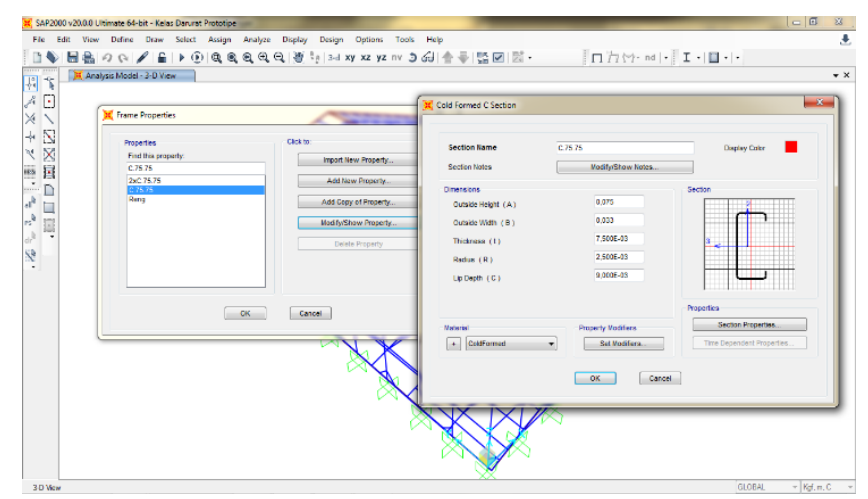

Figure 11. Input material profile data.

5. Loading (load area)

After filling the material specifications, the next is filling the loading, which includes: self load, roof cover load, and wind load.

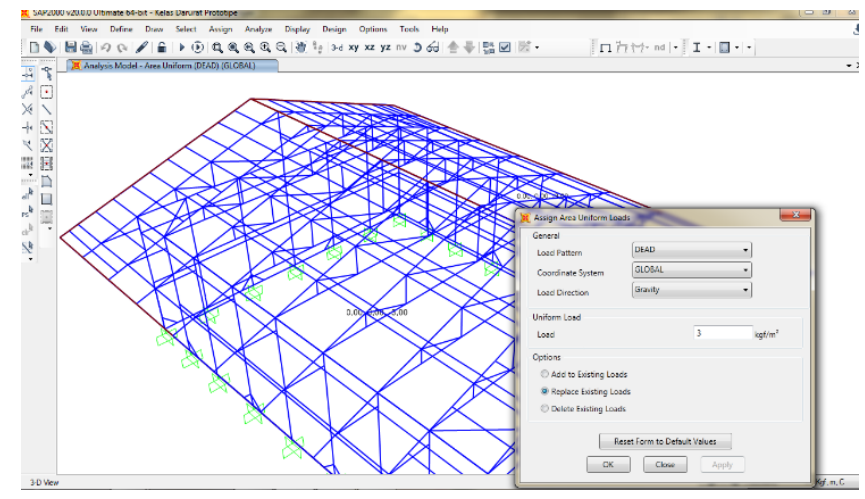

Figure 12. Input loading data.

6. Results of analysis (stress ratio)

After analyzing both the structure of the roof truss and the wall truss, below is an output picture of the results of the analysis using SAP 2000 software.

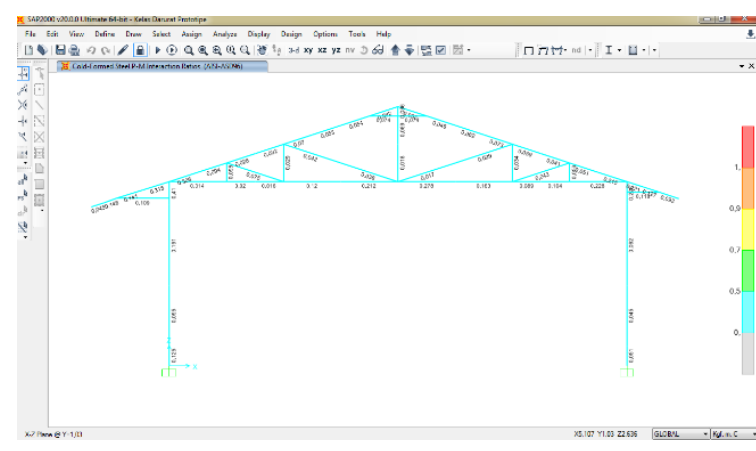

Figure 13. The stress ratio simulation results.

\section{Temporary Classroom Implementation Guidelines}

From the results of the above analysis, the Temporary Classroom work guidelines can be arranged as follows:

\section{Preparatory Work}

Preparatory work includes measuring, preparing equipment and materials to establish Temporary Classrooms. Materials used include:

a. Mild steel C 0.75 with a thickness of $1 \mathrm{~mm}$

b. Mild steel 0.40 for batten

c. Mild steel screw

d. $4 \mathrm{~mm}$ GRC Board

The GRC board chosen for use in this Emergency Class Room building is a GRC board with a thickness of $4 \mathrm{~mm}$. This selection is based on the availability of the volume of material in the location affected by the earthquake, namely Lombok.

e. Spandek

Spandek used with a length of $4 \mathrm{~m}$ and $6 \mathrm{~m}$ with a thickness of $0.3 \mathrm{~mm}$. Due to these specifications, it is rather difficult to find in Lombok, and is only served by factory orders.

f. Cement, sand, stone and coral

The foundation of the Temporary Classroom building uses mortar, sand, and river stone. While for the work floor use mortar, sand and coral.

Tools used include:

a. Electric hand drill

b. Light steel scissors

c. Lightweight steel screw driver (driver)

d. Key driver for GRC board couplers

e. Concrete mixer

\section{Foundation Work and Work Floor}

If all materials and tools are available, then measurements will be continued. After measuring and determining the foundation point. It must be ensured that the building will be made in the position of the elbow. Used iron / wood stakes, after getting the elbow points used nylon 


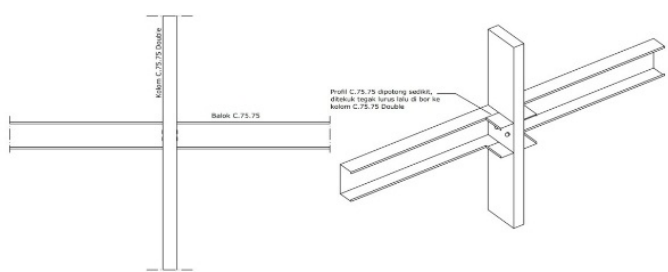

Fig 17. Stiffening Beams on the Middle Section of the Column

\section{Roof Frame Structure Work}

In the installation of roof truss, the work is divided into two stages, namely;

a. Fabrication

The first step is to cut the top chord, the bottom chord and the web according to the working drawings. In order to be more effective and efficient in the consumption of materials, a cutting plan can be made first. The next step is to arrange the rods according to the working drawings. the last is to lock joint connections using Drilling Screw 12-20.

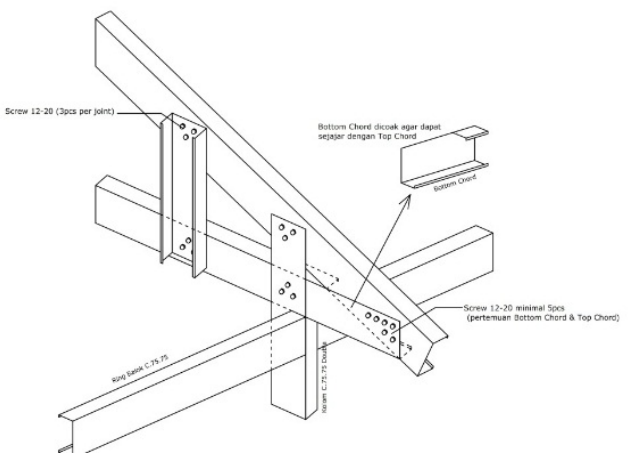

Fig 18. Bottom Chord and Top Chord of Easel Detail

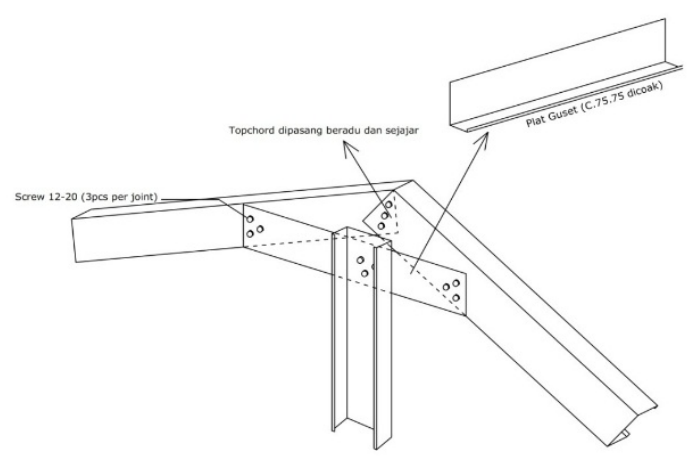

Fig 19. Detail of Top Chord Instalation
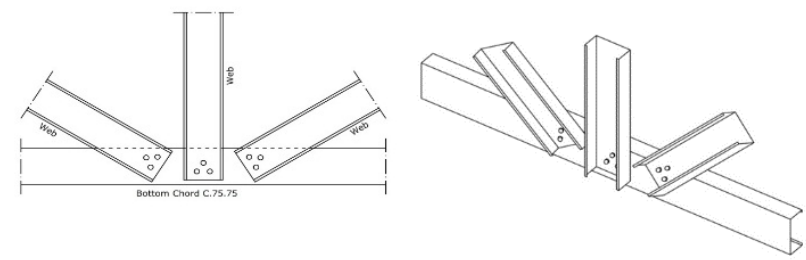

Fig 20. Detail of Bottom Chord Instalation 
b. Easel Erection

After the easel have been fabricated, the next step is erection. To ensure that the level of the horses on both sides are the same, water pass can be used and when the reference level is obtained, then pull the thread from the end to the other end of the easel in two sides. The process of establishing and connecting between horses can be helped tied with battens.

\section{Roof Cover Work}

Roof cover work is divided into 3 stages: batten work and wind ties, consul work, and roof work.

a. Batten Work and Wind Bonds

Wind ties are used to provide stiffeners between the easel, in the picture below, the wind bonding rod connects the bottom chord to the horses. Then it is continued with the installation of battens.

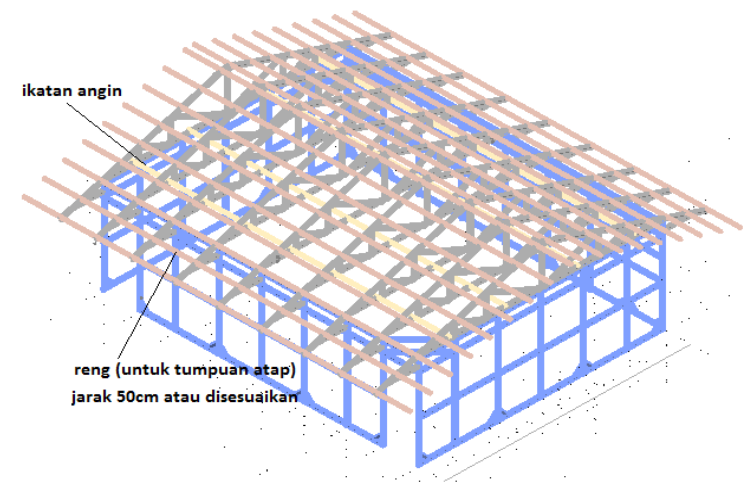

Fig 21. Wind Bond Installation Details.

In addition, a bond is added to the overstek tip, as shown in the following picture.

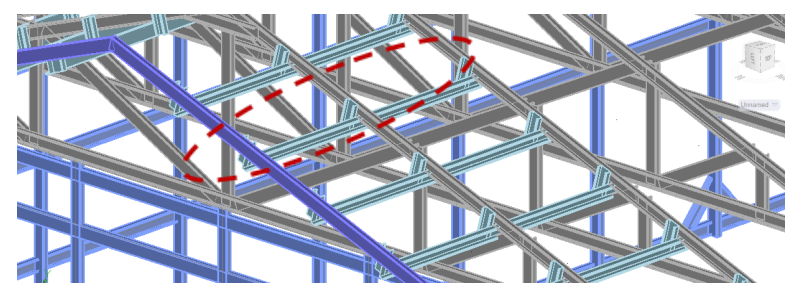

Fig 22. Details of mounting wind ties on the Top Chord

b. Overstek Work

At the end of the sloping stem the consul added easels that supported overstek.

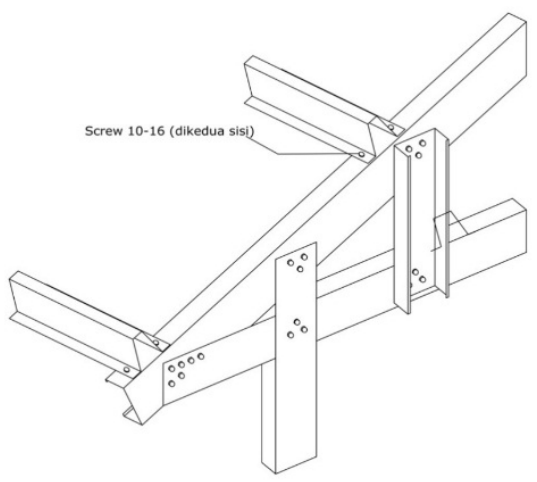

Fig 23. Detailed installation of battens and consuls.

c. Roof Work

Installation of roof cover made from spandek is done after the batten is installed. Mounting on battens using roofing bolts and assisted by a drill with a suitable locking end.

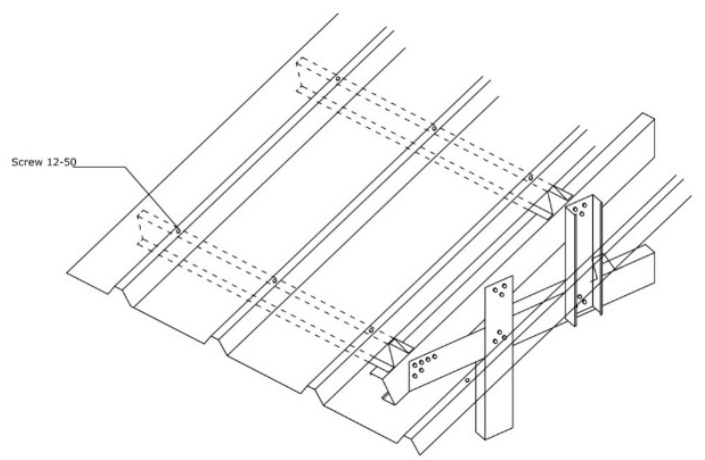

Fig 24. Details of spandek roofing.

\section{Wall Work}

The last job is to install the GRC board wall on the installed frame. In the middle of the column is given a stiffening block. And continued with the installation of the GRC board in an upright position, 1 sheet intact without being cut, as shown below.

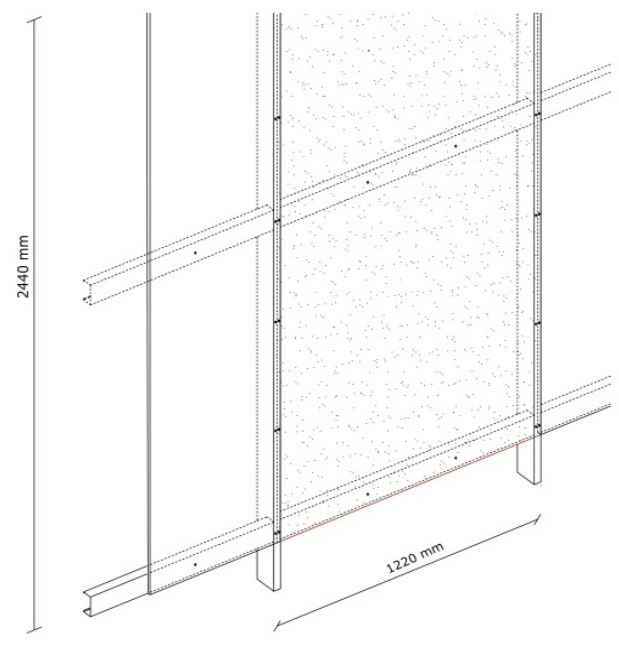

Fig 25. GRC Board Installation Details. 


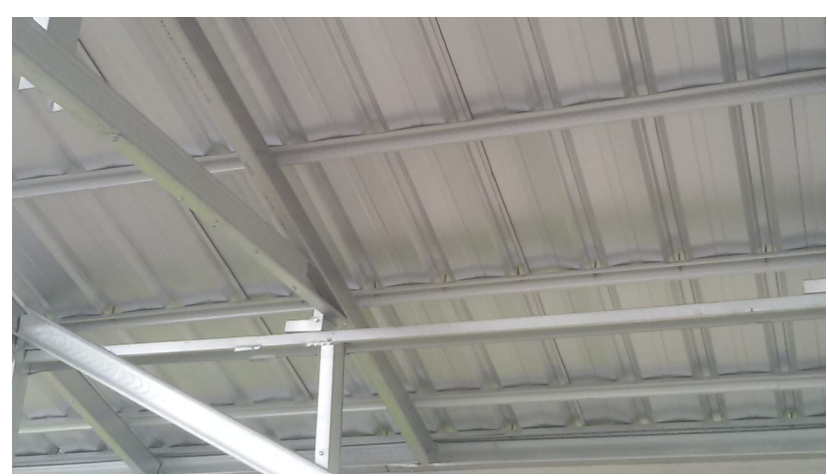

Fig 29. Laying easel and wind ties.

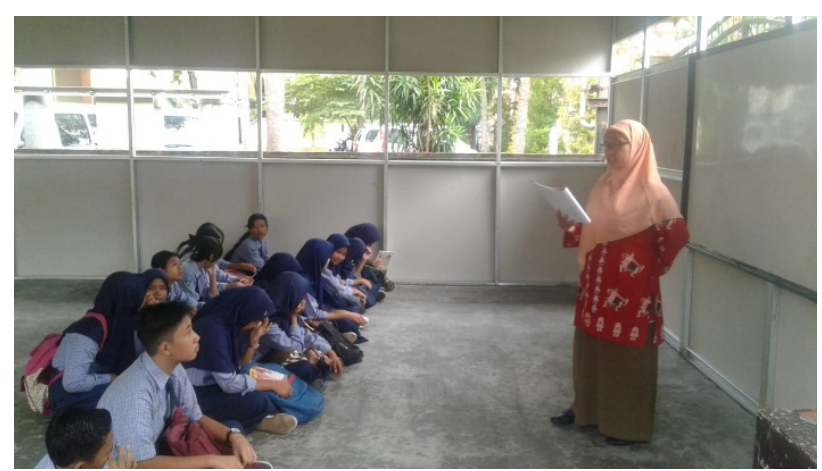

Fig 30. Temporary Classrooms that have been functioned.

\section{CONCLUSION}

Start from the collection of data on temporary classrooms, simulation steps using software, formulation of guidelines for the construction of temporary classrooms and their experiments, it can be concluded that temporary classrooms that are erected using lightweight structures and carried out with easy processes in large numbers must pay attention safety structure, especially in areas affected by earthquakes still often occur tremors. This study reviews the temporary classrooms which serve as a learning container when the classrooms that were collapsed by the earthquake are being repaired, so that further research can be carried out on how the Temporary Classroom continues if the permanent building is built, because it contributes to construction waste.

\section{REFERENCES}

[1] Y. P. Prihatmaji, W. B. Pramono, C. A. Nugroho, T. Industri, and U. Islam, "Penyuluhan bangunan rumah tahan gempa sebagai optimalisasi mitigasi gempa bumi," vol. 2, no. 3, pp. 233-239, 2013.

[2] UU No. 28 Tentang Bangunan, "UU No. 28 Thn 2002 Tentang Bangunan,” pp. 1-53, 2002.

[3] Y. Hong, "A study on the condition of temporary housing following disasters: Focus on container housing," Front. Archit. Res., vol. 6, no. 3, pp. 374383, 2017.

[4] M. Schlaich and C. Engineers, "Lightweight structures," Build. Res. Inf., vol. 20, no. 1, pp. 14-15, 1992.

[5] M. L. Kurnia, "Pelaksanaan Kebijakan Rehabilitasi

Fig 28. Bottom Chords, Top Chords, and Easel Web on the roof structure. 
BAJA RINGAN DENGAN DINDING PAPAN SERAT SEMEN ( RUKOM ) Design of Seismic Resistant Prefabricated House Using Lightwe ....," no. September, 2016. 